\title{
Charente-Maritime, Charente et Deux-Sèvres
}

Patrick Joy

URL : http://journals.openedition.org/adlfi/1141

ISSN : 2114-0502

Éditeur

Ministère de la culture

Référence électronique

Patrick Joy, "Charente-Maritime, Charente et Deux-Sèvres », ADLFI. Archéologie de la France-

Informations [En ligne], Poitou-Charentes, mis en ligne le 01 mars 2008, consulté le 01 mai 2019. URL :

http://journals.openedition.org/adlfi/1141

Ce document a été généré automatiquement le 1 mai 2019.

(c) Ministère de la Culture et de la Communication, CNRS 


\title{
Charente-Maritime, Charente et Deux-Sèvres
}

\author{
Patrick Joy
}

Identifiant de l'opération archéologique : 204493

Date de l'opération : 2008 (PA)

À la demande du service régional de l'Archéologie, les survols, en 2008, ont concerné l'ensemble thermal de Chassenon, et la future Ligne à Grande Vitesse Tours-Bordeaux sur sa partie Charente. Sur ce tracé, les survols ont permis de découvrir un ensemble d'enclos fossoyés sur Villognon, Luxé, et Courcôme.

Par ailleurs, ont été survolés les chantiers de fouilles programmées portant sur les enclos circulaires de Puyréaux, site découvert lors d'une prospection précédente, sur l'enceinte néolithique de Chenommet et sur la villaantique de Jonzac en Charente-Maritime.

Les survols ont également permis la découverte d'une enceinte néolithique à Rouillac, avec quatre entrées visibles, une autre à Verteuil, des ensembles d'enclos circulaires à Biron et à Saint-Seurin-de-Palenne.

Depuis 2007, un inventaire des mottes et fortifications des Deux-Sèvres est en cours. La campagne 2008 a permis de présenter celles d'Ardilleux et de Bouin.

JOY Patrick 
INDEX

Index chronologique : Néolithique

operation Prospection aérienne (PA)

Thèmes : enceinte, enclos, enclos circulaire, fortification, motte

Index géographique : Poitou-Charentes, Charente-Maritime (17), Jonzac (17197)

\section{AUTEURS}

PATRICK JOY

BEN 